\title{
Irrigação na produção de silagem de milho e sorgo, em sucessão ao arroz de terras altas ${ }^{1}$
}

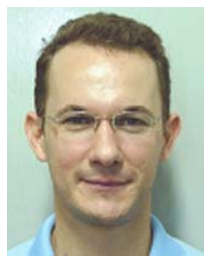

Renato B. Spohr ${ }^{2}$, Marcio F. Maggi ${ }^{3}$, Reimar Carlesso², Jefferson H. Kunz ${ }^{4}$ \& Tatiana T. Fiorin ${ }^{2}$

${ }^{1}$ Parte da Dissertação de Mestrado do primeiro autor apresentada ao Programa de Pós-Graduação em Engenharia Agrícola, Universidade Federal de Santa Maria.

${ }^{2}$ UFSM, Rua Q, Prédio 21, Sala 5010, Santa Maria, RS. CEP 97105-900, Fone: (55)3220-8399, E-mail: renatospohr@mail.ufsm.br (Foto)

${ }^{3}$ Programa de Pós-Graduação em Irrigação e Drenagem/UFSM, Rua Paulo Donato Castellane, s/n, UNESP - Jaboticabal, SP, CEP 14884-900, (14)3811-7100, marciofm@fca.unesp.br

${ }^{4}$ Programa de Pós-Graduação em Fitotecnia/UFRGS, Av. Bento Gonçalves, 7712, Porto Alegre, RS, CEP 91540-000, Fone: (55)3316-7437. E-mail: jefkunz@yahoo.com.br

Protocolo $9-9 / 2 / 2004$ - Aprovado em 5/5/2005

Resumo: Tendo em vista o propósito de se avaliar épocas de semeadura para maximizar a produção de arroz de terras altas e de milho e sorgo em sucessão e avaliar o retorno econômico desse sistema de produção irrigado, na região de Santa Maria, RS, conduziu-se este trabalho em área experimental do Departamento de Engenharia Rural da Universidade Federal de Santa Maria, no ano agrícola 2001/2002. Conduziu-se dois experimentos em delineamento experimental de blocos ao caso, com quatro repetições. O primeiro experimento constituiu-se de quatro datas de semeadura do arroz (18 de setembro, 4 de outubro, 19 de outubro e 5 de novembro); no segundo experimento foram utilizadas as seguintes datas de semeadura do milho e do sorgo, semeados após a colheita do arroz, em 28 de janeiro, 8 de fevereiro, 20 de fevereiro e 5 de março. As datas de semeadura do arroz ocasionaram diferenças no rendimento de grãos, apresentando a máxima eficiência técnica (5,80 $\left.\mathrm{Mg} \mathrm{ha}^{-1}\right)$ na semeadura estimada de 13 de outubro. Na sucessão de culturas irrigadas de arroz de terras altas para produção de grãos e sorgo para produção de silagem, a maior receita líquida foi observada com a semeadura do arroz, na segunda quinzena de setembro.

Palavras-chave: rotação de culturas, zoneamento agrícola, massa seca

\section{Production of maize and sorghum for silage in succession to the upland rice}

\begin{abstract}
The objective of this work was to evaluate different sowing dates to maximize doublecropping (upland rice followed by either maize or sorghum) and evaluate the economica practicability of this production system in the region of Santa Maria, in the State of Rio Grande do Sul. Two experiments were conducted in the experimental field of the Agricultural Engineering Department of the Federal University of Santa Maria - RS, Brazil, during the 2001/2002 growing season. A randomized block design was used with four replications. Treatments of the first experiment were constituted of four sowing dates of upland rice: September 18, October 4, October 19 and November 5. The treatments of the second experiment were constituted of four sowing dates of maize and sorghum (after the harvest of the upland rice): January 28, February 8, February 20 and March 5. The upland rice sowing dates caused differences in grain yield and the maximum technical efficiency (5.80 $\mathrm{Mg} \mathrm{ha}^{-1}$ ) was observed for the rice sown on October 13 . The use of double-cropping cultivation in the southern half of Rio Grande do Sul the State upland rice followed by sorghum for the production of silage, for maximum retnans, the upland rice should be sown during de second half of September.
\end{abstract}

Key words: crop rotation, agricultural zoning, dry matter 


\section{INTRODUÇÃO}

No Rio Grande do Sul tem-se registrado, nas últimas décadas, aumento nas desigualdades regionais, caracterizadas pela concentração de população e de renda em algumas dessas áreas, enquanto em outras, agravam-se os problemas estruturais da economia, gerando redução populacional e empobrecimento. Dentro desse contexto destaca-se negativamente a Metade Sul, região predominantemente agropecuária, na qual as principais atividades econômicas são a orizicultura e a pecuária de corte. Esta região vem sofrendo, ao longo das últimas décadas, profundo processo de perda de dinamismo econômico, dificultando o seu desenvolvimento econômico e social.

Cultivares de arroz de terras altas muito produtivas têm despertado o interesse de inúmeros produtores do Rio Grande do Sul, principalmente dos que possuem sistema de irrigação por aspersão em suas propriedades. O arroz de terras altas surge como opção em um sistema de rotação por apresentar ciclo curto, com grande produção de massa seca, no qual se utiliza, predominantemente, o milho, o feijão e a soja.

A silagem de milho ou sorgo pode ser uma alternativa na intensificação da atividade da pecuária de corte, suprindo a carência alimentar durante o inverno no RS, contribuindo para a redução na idade de abate, incrementando os índices reprodutivos dos rebanhos bovinos do Estado (Restle et al., 2000). A utilização do milho e do sorgo na alimentação de bovinos, principalmente devido à qualidade da silagem, agrega valor ao produto e aumenta a lucratividade da atividade agropecuária.

O cultivo do milho e do sorgo para silagem em sucessão ao arroz de terras altas irrigado por aspersão visa a melhoria do sistema de produção em busca da sua sustentabilidade na atividade agrícola, aumentando a receita líquida por área. Para o estabelecimento do arroz e do milho/sorgo em áreas de terras altas, alguns aspectos do processo produtivo da cultura devem ser ajustados em função principalmente das características do clima e do solo; entre esses fatores destaca-se a época de semeadura, que é uma das técnicas de manejo da lavoura que pode ser utilizada para diminuir a variabilidade das condições climáticas, pelo fato de aumentar as chances das plantas escaparem dos períodos em que as condições meteorológicas são adversas à cultura. Segundo Fornasieri Filho (1983) conhecendo-se os efeitos causados pela temperatura, radiação solar, necessidade hídrica e ciclo da cultura, é possível se determinar o período para a semeadura no qual haja maior probabilidade de bons resultados.

A época de semeadura exerce grande influência no crescimento e no desenvolvimento das plantas de milho devido, principalmente, às variações na disponibilidade térmica e de radiação solar. Segundo Moraes de Sá (1993), a época preferencial de semeadura para a cultura do milho é aquela em que a maior área foliar coincide com os dias mais longos do ano, quando não há limitação hídrica. Essas variações estão associadas aos efeitos que a temperatura do ar e a radiação solar exercem sobre o crescimento e os componentes do rendimento de grãos. A caracterização das modificações que ocorrem na planta nas diferentes épocas de semeadura, é importante para definir a adoção das práticas culturais com vistas à maximização da produção em cada época.

A partir do terceiro decêndio do mês de outubro, a temperatura do solo é favorável à semeadura do arroz irrigado em praticamente todas as áreas de várzea no Rio Grande do Sul e, em Santa Maria, de modo particular, a temperatura do solo permite a semeadura no terceiro decêndio de setembro (Steinmetz et al., 2001). EMBRAPA (1999) menciona que a época mais adequada para a semeadura do arroz irrigado se situa entre 15 de outubro e 15 de novembro. Como orientação geral e independente do ciclo, todas as cultivares de arroz podem ser semeadas antes de 15 de outubro no Estado.

Nesse contexto, objetivou-se através deste trabalho avaliar épocas de semeadura para maximizar a produção de arroz de terras altas e de milho e sorgo em sucessão e irrigados por aspersão, e o retorno econômico desse sistema de produção, na região de Santa Maria, RS.

\section{MATERIAL E MÉTODOS}

Dois experimentos foram conduzidos no campo, em área experimental do Departamento de Engenharia Rural da Universidade Federal de Santa Maria, RS, no ano agrícola de 2001/2002. O delineamento experimental utilizado foi blocos ao acaso, com quatro repetições. O solo do local é classificado como Argissolo Vermelho Distórfico Arênico.

No primeiro experimento os tratamentos foram constituídos de quatro datas de semeadura do arroz de terras altas: (i) 18 de setembro (261 dias do ano - DDA); (ii) 4 de outubro (277 DDA); (iii) 19 de outubro (292 DDA) e (iv) 5 de novembro (309 DDA). As parcelas experimentais apresentaram dimensões de $8 \times 6 \mathrm{~m}$ $\left(48 \mathrm{~m}^{2}\right)$. No arroz de terras altas (cultivar Primavera) aplicaramse 12,5 $\mathrm{kg} \mathrm{N} \mathrm{ha}^{-1}, 50 \mathrm{~kg} \mathrm{P}_{2} \mathrm{O}_{5}$ ha $^{-1}$ e $50 \mathrm{~kg} \mathrm{~K}_{2} \mathrm{O} \mathrm{ha}^{-1}$, na fórmula comercial 5-20-20; o restante do nitrogênio, $87,5 \mathrm{~kg} \mathrm{ha}^{-1}$, foi aplicado em três vezes, no início do perfilhamento, no perfilhamento máximo e na diferenciação do primórdio floral. A semeadura foi realizada no sistema de plantio direto, utilizandose semeadora adubadora com espaçamento entre linhas de semeadura de $0,17 \mathrm{~m}$.

A população de plantas da cultura do arroz de terras altas foi de 305, 294, 290 e 403 plantas $\mathrm{m}^{-2}$, para as semeaduras realizadas em 18 de setembro, 4 de outubro, 19 de outubro e 5 de novembro, respectivamente. A colheita e a trilha das panículas de arroz foi feita em uma área de 4 x $6 \mathrm{~m}\left(24 \mathrm{~m}^{2}\right) \mathrm{em}$ cada parcela, e a produção final de grãos corrigida para $13 \%$ de umidade.

No segundo experimento os tratamentos constituíam-se de quatro datas de semeadura do milho e do sorgo para silagem, semeados no mesmo local após a colheita do arroz de terras altas: (i) 28 de janeiro (28 DDA); (ii) 8 de fevereiro (39 DDA); (iii) 20 de fevereiro (51 DDA) e (iv) 5 de março (64 DDA), em parcelas com dimensões de $4 \times 6 \mathrm{~m}\left(24 \mathrm{~m}^{2}\right)$. Os híbridos utilizados foram o Pioneer 3041 e o Pioneer 8419, de milho e sorgo, respectivamente, ambos de ciclo precoce. A adubação aplicada no milho e sorgo foi de $20 \mathrm{~kg} \mathrm{~N} \mathrm{ha}^{-1}, 80 \mathrm{~kg} \mathrm{P}_{2} \mathrm{O}_{5}$ ha $^{-1}$ e $80 \mathrm{~kg} \mathrm{~K}_{2} \mathrm{O}$ $\mathrm{ha}^{-1}$, na fórmula comercial 5-20-20, na semeadura e $130 \mathrm{~kg} \mathrm{ha}^{-1}$ de nitrogênio em cobertura, em duas aplicações de $65 \mathrm{~kg} \mathrm{ha}^{-1}$ na completa expansão da quarta e oitava folhas. Junto à primeira 
aplicação de nitrogênio em cobertura no milho e no sorgo, foram aplicados mais 60 e $40 \mathrm{~kg} \mathrm{ha}^{-1} \mathrm{de}_{2} \mathrm{O}$, respectivamente. O sorgo e o milho foram semeados manualmente, em linha, simulando-se o plantio direto, com espaçamento entre linhas de plantio de 0,50 e $0,70 \mathrm{~m}$, respectivamente.

As populações de plantas das culturas de milho e sorgo foram de 7,2 e 16,5 plantas $\mathrm{m}^{-2}$, respectivamente. A área foliar do milho e sorgo foi obtida pelo produto do comprimento pela largura máxima de cada folha multiplicada pelo fator 0,75 , enquanto o índice de área foliar foi calculado pela razão entre a área foliar fotossinteticamente ativa da planta e a superfície do solo ocupada por essa planta. Determinou-se a massa verde da parte aérea das plantas de milho colhendo-se uma área de $8,4 \mathrm{~m}^{2}$ (12 m lineares) e, para o sorgo, colhendo-se $8 \mathrm{~m}^{2}(16 \mathrm{~m}$ lineares).

A irrigação foi realizada por um sistema de aspersão convencional fixo, instalado na área experimental. A necessidade de irrigação foi determinada com base no programa de manejo da irrigação do Sistema Irriga ${ }^{\circledR}$, disponível no site http://www.irriga.proj.ufsm.br. A metodologia do cálculo foi a estimativa da evapotranspiração de referência (ETo) pelo método de Penman-Monteith. A evapotranspiração máxima das culturas $(\mathrm{ETm}=\mathrm{ET}$ $\mathrm{x} \mathrm{Kc})$ foi estimada pelo método de PenmanMonteith parametrizado pela FAO, utilizando os valores dos coeficientes de cultura $(\mathrm{Kc})$ propostos por Doorenbos \& Kassam (1979).

O retorno econômico dos custos de produção foi definido contabilizando-se todos os custos diretos e indiretos envolvidos na produção: insumos, mão-de-obra, valor da terra, depreciação, irrigação, preparo do solo, colheita etc. Os custos de produção relacionados à irrigação foram determinados através da lâmina média de irrigação aplicada. A análise estatística foi realizada através do programa Statistical Analysis System (SAS), sendo a análise de variância e regressão dos resultados determinados em nível de $5 \%$ de probabilidade de erro.

\section{RESULTADOS E DISCUSSÃO}

A precipitação pluvial durante o ciclo de desenvolvimento da cultura do arroz de terras altas foi de 460, 396, 393 e 399 mm, para as semeaduras realizadas em 18 de setembro, 4 de outubro, 19 de outubro e 5 de novembro, respectivamente. Foram aplicados, em média $327 \mathrm{~mm}$ de água via irrigação para cada ciclo de cultivo. A precipitação pluvial verificada durante os ciclos de desenvolvimento da cultura do milho e sorgo, foi de $632,585,794$ e $727 \mathrm{~mm}$, para as semeaduras realizadas em 28 de janeiro, 8 de fevereiro, 20 de fevereiro e 5 de março, respectivamente. Aplicaram-se em média $150 \mathrm{~mm}$ de água via irrigação para cada data de semeadura. Os valores de temperatura média e mínima do ar e de radiação solar durante o desenvolvimento dos cultivos, são apresentados na Figura 1.

O índice de área foliar das plantas de milho foi crescente até o florescimento, quando se observaram os maiores valores, que foram de 3,9, 4,5, 4,7 e 4,4 para as semeaduras realizadas em 28 de janeiro, 8 de fevereiro, 20 de fevereiro e 5 de março, respectivamente; esses valores são maiores que os encontrados por Garcia (2002), que obteve valores máximos de índice de área foliar de 3,8.

Os valores de índice de área foliar das plantas de sorgo no florescimento foram de 5,8, 4,6, 4,6 e 4,2, para as semeaduras realizadas em 28 de janeiro, 8 de fevereiro, 20 de fevereiro e 5 de março, respectivamente. $\mathrm{O}$ sorgo semeado em 28 de janeiro

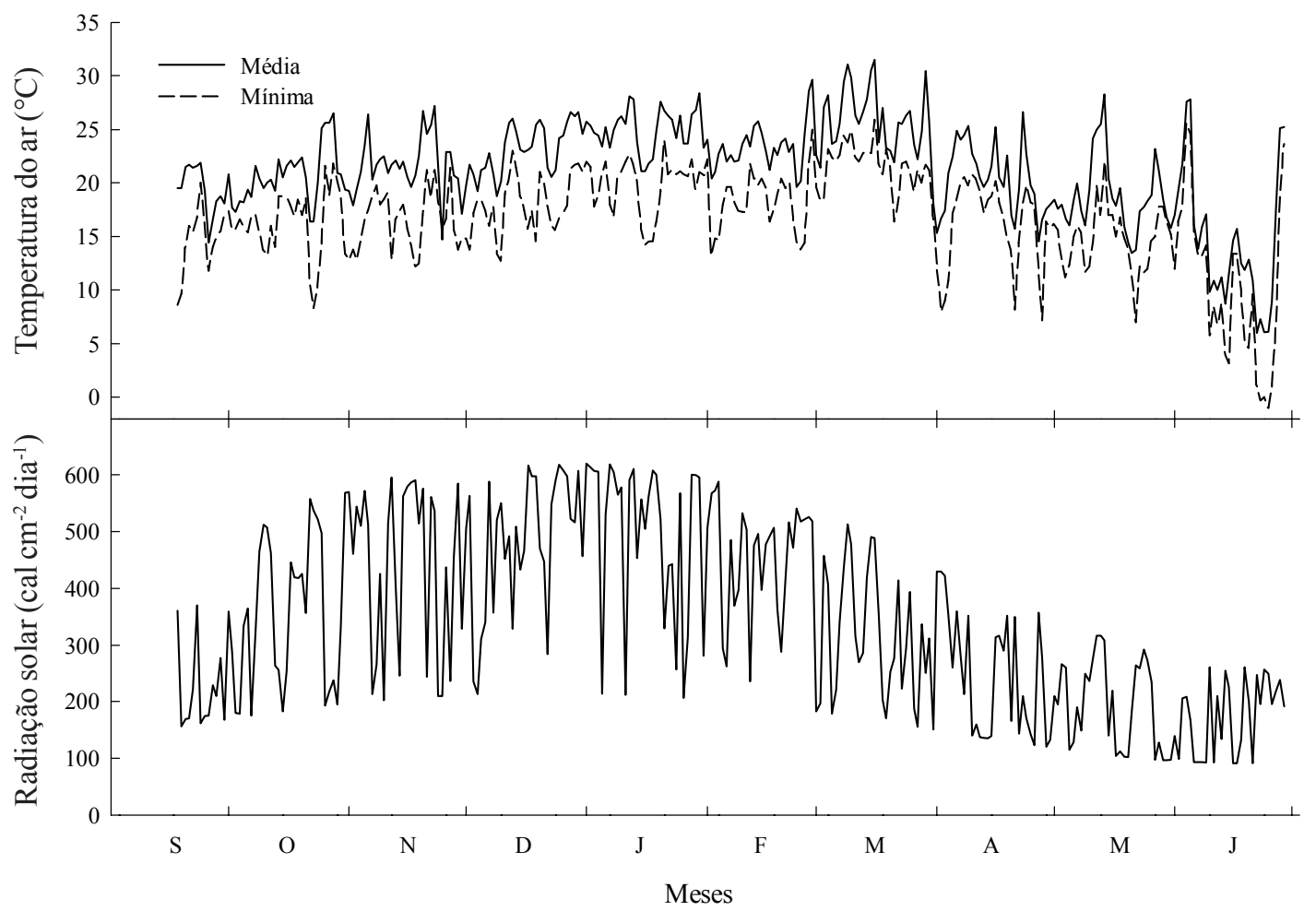

Figura 1. Valores de temperatura mínima e média do ar e radiação solar ocorridos durante o ciclo de desenvolvimento das plantas de arroz de terras altas, milho e sorgo para silagem. Santa Maria, RS, 2003 
apresentou maior índice de área foliar no período do florescimento, quando comparado com as demais datas de semeadura, devido às maiores temperaturas e radiação solar ocorridas neste período (Figura 1). Com o retardamento da semeadura, o índice de área foliar no florescimento reduziu. Peiter (1994) trabalhando com sorgo granífero submetido a diferentes níveis de irrigação, obteve índices de área foliar semelhantes, com valores variando de 4,5 a 5,5.

Os resultados do quadrado médio da análise da variância para a massa verde acumulada das plantas de milho e sorgo, rendimento de grãos de arroz de terras altas e a soma das receitas líquidas (arroz de terras altas + milho silagem e arroz de terras altas + sorgo silagem) são apresentados na Tabela 1.

O rendimento de grãos do arroz de terras altas foi diferente entre as quatro datas de semeadura (Figura 2) e se observou um comportamento quadrático com o retardamento na data de semeadura de 18 de setembro para 5 de novembro. Este comportamento está diretamente relacionado ao número de grãos cheios por panícula (máxima eficiência técnica de 98,8 grãos para a semeadura realizada em 9 de outubro) e, também, em razão da menor disponibilidade de radiação solar e

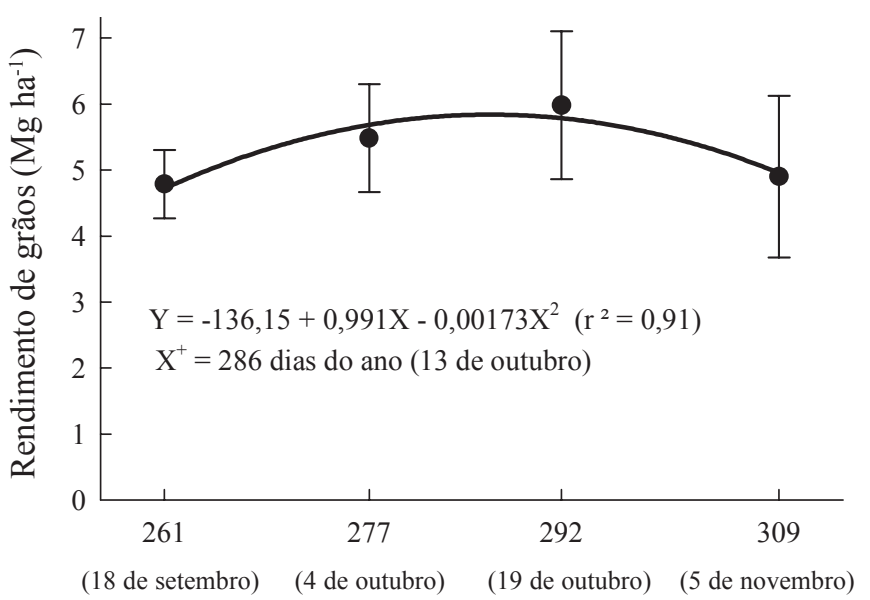

Dias do ano

Figura 2. Rendimento de grãos de arroz de terras altas, irrigado por aspersão. As bandas verticais representam o desvio padrão temperaturas mais baixas no período entre o florescimento e a maturação fisiológica observada para a última data de semeadura. A máxima eficiência técnica para o rendimento de grãos foi de 5,8 $\mathrm{Mg} \mathrm{ha}^{-1}$ para semeadura estimada em $13 \mathrm{de}$ outubro (286 dias do ano), cujos valores estão abaixo dos encontrados por Toescher \& Köpp (2002) que obtiveram 6,75 $\mathrm{Mg} \mathrm{ha}^{-1}$ para a mesma cultivar, semeada em 22 de novembro e irrigada por aspersão em Uruguaiana, RS.

Na Figura 3 observa-se redução na massa verde acumulada do milho e sorgo, com o retardamento na data de semeadura. A massa verde acumulada da cultura do milho e do sorgo apresentou comportamento linear decrescente entre as datas de semeadura. A maior produção de massa verde acumulada de milho (34,0 $\mathrm{Mg} \mathrm{ha}^{-1}$ ) e sorgo (31,2 $\mathrm{Mg} \mathrm{ha}^{-1}$ ) foi obtida quando a semeadura foi realizada em 28 de janeiro (28 dias do ano). A redução na disponibilidade de radiação solar e as baixas temperaturas nos meses de outono são as prováveis causas para a redução na produção de massa verde e seca acumuladas do milho e sorgo (Figura 1); além disso, a ocorrência de uma geada quando as plantas do milho se encontravam no estádio de grão leitoso causou a morte das plantas e a antecipação na

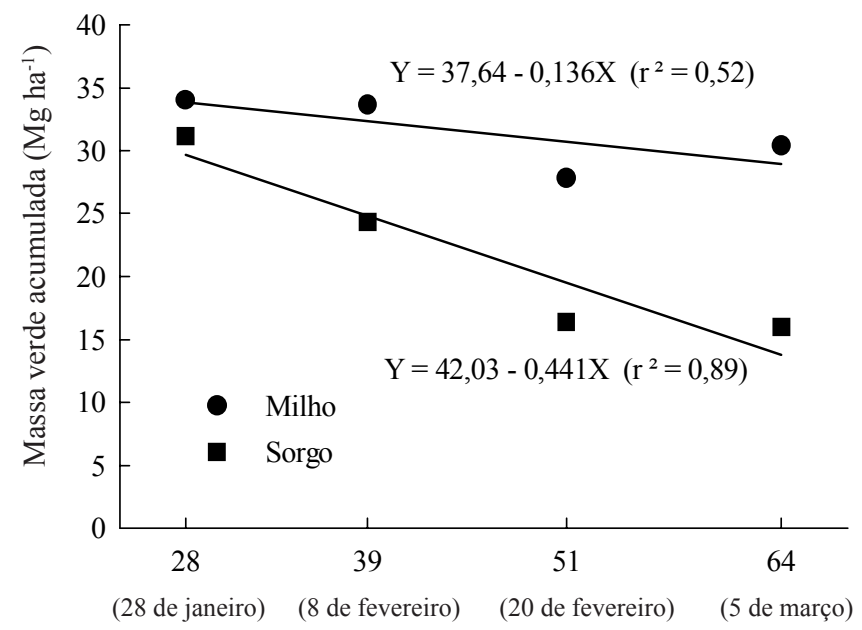

Dias do ano

Figura 3. Massa verde acumulada de milho e sorgo semeados em sucessão ao arroz de terras altas

Tabela 1. Quadrado médio da análise de variância para o rendimento de grãos das plantas de arroz de terras altas, massa verde acumulada e a soma das receitas líquidas (arroz de terras altas + milho silagem e arroz de terras altas + sorgo silagem) para as quatro diferentes datas de semeadura

\begin{tabular}{|c|c|c|c|c|c|c|}
\hline \multicolumn{7}{|c|}{ Causas de variação } \\
\hline \multirow[t]{2}{*}{ Cultura } & Bloco & Data de Semeadura & Modelo Linear & Modelo Quadrático & Resíduo & $\mathrm{CV}(\%)$ \\
\hline & GL 3 & 3 & 1 & 1 & 9 & \\
\hline \multirow[t]{2}{*}{ Arroz } & $3,83 *$ & $1,12 *$ & $0,06 \mathrm{~ns}$ & $2,94 *$ & 0,25 & 9,25 \\
\hline & \multicolumn{6}{|c|}{ Massa verde acumulada } \\
\hline Milho & $0,002 \mathrm{~ns}$ & $0,347 *$ & $0,549 *$ & $0,126 \mathrm{~ns}$ & 0,034 & 5,84 \\
\hline & \multicolumn{6}{|c|}{ Soma das receitas líquidas } \\
\hline Arroz + Milho & $1410591,4 *$ & $326677,0 \mathrm{~ns}$ & $46559,4 \mathrm{~ns}$ & $933419,2 \mathrm{~ns}$ & 134593,5 & 14,58 \\
\hline Arroz + Sorgo & $1752824,7 *$ & $1181189,7 *$ & $3216743,4 *$ & $326390,0 \mathrm{~ns}$ & 157155,6 & 15,67 \\
\hline
\end{tabular}

* Significativo em nível de probabilidade 0,05 ; ns - Não significativo em nível de probabilidade de 0,05; CV = Coeficiente de Variação; GL = Graus de Liberdade 
determinação da massa verde acumulada para a semeadura realizada em 5 de março (64 dias do ano). Portanto, os riscos de ocorrer a morte de plantas, devido a geadas, aumenta a medida em que ocorre o retardamento na data de semeadura do milho e sorgo para silagem. Chielle (1995) encontrou uma produção média de massa verde total de sorgo semeado em novembro variando, de 26,4 a 34,8 $\mathrm{Mg} \mathrm{ha}^{-1}$. Na utilização da sucessão de culturas do arroz de terras altas para produção de grãos e milho/sorgo para a silagem, é conveniente avaliar o incremento no rendimento de grãos do arroz de terras altas e a redução na massa fresca e seca acumuladas do milho e sorgo, com o retardamento na data de semeadura. Para se determinar a melhor data de semeadura do arroz de terras altas e do milho/sorgo para silagem, deve-se somar as receitas líquidas dos dois cultivos (arroz de terras altas + milho silagem e arroz de terras altas + sorgo silagem) para cada uma das datas de semeadura avaliadas. A receita líquida é a diferença entre a receita bruta e os custos de produção de um cultivo agrícola. Os custos de produção para o arroz de terras altas e milho/sorgo para silagem, determinados para uma área média de 100 ha, são apresentados na Tabela 2. Considerou-se o preço comercial de $\mathrm{R} \$ 32,00$ para a saca de $50 \mathrm{~kg}$ de arroz. Foi considerado um preço comercial de $\mathrm{R} \$ 58,50$ a tonelada de massa verde do milho para silagem, calculado através do custo de produção médio por tonelada de massa verde para as quatro datas de semeadura $(\mathrm{R} \$ 45,00)$ mais $30 \%$ como margem de lucro. O mesmo cálculo foi realizado para determinação do preço comercial de $\mathrm{R} \$ 84,50$ a tonelada de massa verde do sorgo para silagem, cujo custo de produção médio por tonelada de massa verde foi de $\mathrm{R} \$ 65,00$.

A soma das receitas líquidas (arroz de terras altas + milho silagem e arroz de terras altas + sorgo silagem) é apresentada na Figura 4, cujos resultados indicaram que a receita líquida não foi significativa para as diferentes datas de semeadura do arroz de terras altas e milho silagem e a receita líquida média foi de $\mathrm{R} \$ 2.513,00 \mathrm{ha}^{-1}$; já a receita líquida para as diferentes datas de semeadura do arroz de terras altas e sorgo silagem, apresentou comportamento linear e a maior receita líquida $\left(\mathrm{R} \$ 2.986,08 \mathrm{ha}^{-1}\right)$ foi observada para a semeadura do arroz de terras altas realizada

Tabela 2. Custos de produção do arroz de terras altas e milho/sorgo

\begin{tabular}{|c|c|c|c|c|c|c|c|c|}
\hline \multirow[b]{2}{*}{ Componente do custo } & \multicolumn{4}{|c|}{ Arroz de terras altas } & \multicolumn{4}{|c|}{ Milho / Sorgo (silagem) } \\
\hline & $\begin{array}{c}\text { Unidade } \\
\text { ha }^{-1}\end{array}$ & Unidade & $\begin{array}{c}\mathrm{R} \$ \\
\text { Unidade }^{-1}\end{array}$ & $\begin{array}{c}\mathrm{R} \$ \\
\mathrm{ha}^{-1}\end{array}$ & $\begin{array}{c}\text { Unidade } \\
\text { ha }^{-1}\end{array}$ & Unidade & $\begin{array}{c}\text { RS } \\
\text { Unidade }^{-1}\end{array}$ & $\begin{array}{l}\mathrm{R} \$ \\
\mathrm{ha}^{-1}\end{array}$ \\
\hline \multicolumn{9}{|c|}{ Operacional } \\
\hline Semeadura & 1 & $\mathrm{v}$ & 28,46 & 28,46 & 1 & $\mathrm{v}$ & 28,46 & 28,46 \\
\hline Adubação de cobertura & 2 & $\mathrm{v}$ & 12,58 & 25,16 & 2 & $\mathrm{v}$ & 12,58 & 25,16 \\
\hline Aplicação de herbicida & 2 & $\mathrm{v}$ & 9,77 & 19,54 & 2 & $\mathrm{v}$ & 9,77 & 19,54 \\
\hline Aplicação de inseticida & 2 & $\mathrm{v}$ & 9,77 & 19,54 & 2 & $\mathrm{v}$ & 9,77 & 19,54 \\
\hline Aplicação de fungicida & 2 & $\mathrm{v}$ & 9,77 & 19,54 & - & - & - & - \\
\hline Colheita & 1 & $\mathrm{v}$ & 41,59 & 41,59 & 1 & $\mathrm{v}$ & 41,59 & 64,64 \\
\hline \multirow[t]{2}{*}{ Transporte interno } & 105 & $\mathrm{sc}$ & 0,53 & 55,91 & 30 & $\mathrm{Mg}$ & 2,48 & 74,54 \\
\hline & & & & 209,73 & & & & 231,87 \\
\hline \multicolumn{9}{|c|}{ Insumos } \\
\hline Semente & 160 & $\mathrm{~kg}$ & 0,56 & 89,60 & 18 & $\mathrm{~kg}$ & 6,00 & 108,00 \\
\hline Fertilizante na base & 0,25 & $\mathrm{Mg}$ & 660,00 & 165,00 & 0,30 & $\mathrm{Mg}$ & 660,00 & 198,00 \\
\hline Adubo cobertura & 0,10 & $\mathrm{Mg}$ & 620,00 & 62,00 & 0,30 & $\mathrm{Mg}$ & 620,00 & 186,00 \\
\hline Dessecante & 3 & 1 & 10,87 & 32,61 & 3 & 1 & 10,87 & 32,61 \\
\hline Herbicida 1 & 3 & 1 & 15,00 & 45,00 & 3 & 1 & 10,00 & 30,00 \\
\hline Herbicida 2 & 10 & 1 & 5,00 & 50,00 & 2 & 1 & 42,00 & 84,00 \\
\hline Herbicida 3 & 0,75 & 1 & 13,00 & 9,75 & - & - & - & - \\
\hline Inseticida & 0,15 & 1 & 60,00 & 9,00 & 0,10 & 1 & 14,58 & 1,46 \\
\hline Fungicida & 0,5 & $\mathrm{~kg}$ & 20,00 & 10,00 & - & - & - & - \\
\hline \multirow[t]{2}{*}{ Espalhante adesivo } & 0,5 & 1 & 6,00 & 3,00 & 0,5 & 1 & 6,00 & 3,00 \\
\hline & & & & 475,96 & & & & 643,07 \\
\hline \multicolumn{9}{|c|}{ Irrigação } \\
\hline Aplicação da lâmina & 300 & $\mathrm{~mm}$ & 0,45 & 135,00 & 150 & $\mathrm{~mm}$ & 0,45 & 67,50 \\
\hline \multirow[t]{2}{*}{ Depreciação } & 1 & ha & 84,00 & 84,00 & 1 & ha & 84,00 & 84,00 \\
\hline & & & & 219,00 & & & & 151,50 \\
\hline \multicolumn{9}{|c|}{ Outros } \\
\hline Mão-de-obra & 3 & $\mathrm{p}$ & 41,40 & 124,20 & 3 & $\mathrm{p}$ & 46,60 & 139,80 \\
\hline Oportunidade da terra & 6,5 & $\%$ & $3.000,00$ & 195,00 & 6,5 & $\%$ & $3.000,00$ & 195,00 \\
\hline Encargos contratuais & & & & 46,91 & & & & 60,72 \\
\hline \multirow[t]{2}{*}{ Assistência técnica } & & & & 14,70 & & & & 16,10 \\
\hline & & & & 380,81 & & & & 411,62 \\
\hline Custo ha ${ }^{-1}\left(\mathrm{R} \$\right.$ ha $\left.^{-1}\right)$ & & & & $1.285,50$ & & & & $1.438,06$ \\
\hline
\end{tabular}




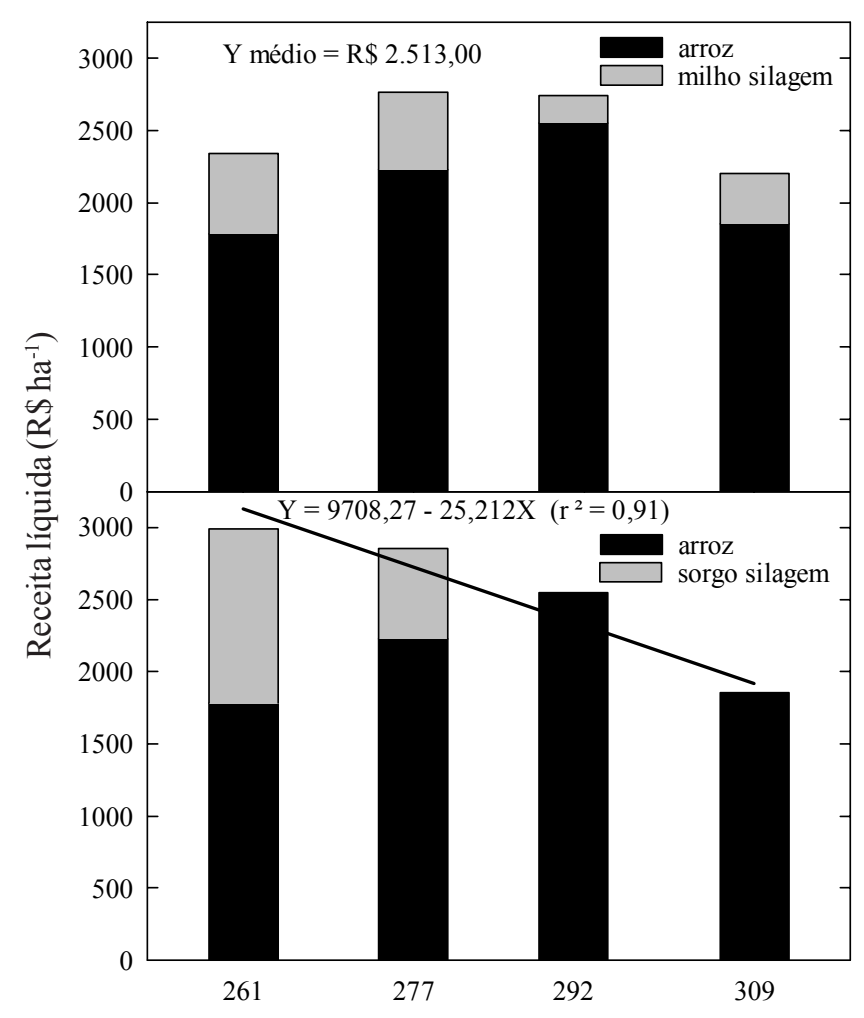

(18 de setembro) (4 de outubro) (19 de outubro) (5 de novembro) Dias do Ano

Figura 4. Soma das receitas líquidas do arroz de terras altas + milho silagem e do arroz de terras altas + sorgo silagem

em 18 de setembro (261 dias do ano). A baixa produtividade de massa verde de sorgo para silagem gerou uma receita líquida negativa, para a semeadura do arroz de terras altas realizada em 19 de outubro e 5 de novembro

\section{CONCLUSÕES}

1. Na sucessão de culturas irrigadas de arroz de terras altas para produção de grãos e sorgo para produção de silagem, a maior receita líquida foi constatada com a semeadura do arroz na segunda quinzena de setembro $\left(\mathrm{R} \$ 2.986,08 \mathrm{ha}^{-1}\right)$.

2. A receita líquida da sucessão de culturas arroz de terras altas e milho silagem não foi influenciada pela data de semeadura do arroz de terras altas.

3. A semeadura do arroz de terras altas na primeira quinzena de outubro resulta em maiores valores de rendimento de grãos $\left(5,8 \mathrm{Mg} \mathrm{ha}^{-1}\right)$.

\section{LITERATURA CITADA}

Chielle, Z.G. Avaliação do sorgo granífero (Sorghum bicolor. Moench) sob diferentes manejos e momentos de semeadura em solo de várzea. Santa Maria: UFSM. 1995. 50p. Dissertação Mestrado

Doorembos, J.; Kassam, A.H. Efectos del água el rendimento de los cultivos. Roma : FAO, 1979.212p. Riego y Drenage, 33

EMBRAPA - Empresa Brasileira de Pesquisa Agropecuária Clima temperado, arroz irrigado, recomendações técnicas da pesquisa para o sul do Brasil. Pelotas: EMBRAPA Clima Temperado/IRGA/EPAGRI, 1999. 124p. Documento 57

Fornasieri Filho, D. Manejo da cultura do arroz de terras altas: semeadura e cultivos. In: Ferreira, M.E., Santos, A.P., Souza, L.S., Prante, R. (ed.). Simpósio Sobre a Cultura do Arroz de Terras Altas. 1983. Jaboticabal. Anais. Piracicaba: Instituto da Potassa e Fosfato, Instituto Internacional da Potassa, 1983.p.271-281.

Garcia, C.G. Manejo da irrigação do milho baseado na evapotranspiração máxima acumulada da cultura. Santa Maria: UFSM. 2002. 45p. Dissertação Mestrado

Moraes de Sá, J.C. Sistema de produção de milho visando alta produtividade na região dos campos gerais no centro-sul do Paraná. Bull, L.T.; Cantarella, H. (ed.) Cultura do milho, fatores que afetam a produtividade. Piracicaba:Associação Brasileira para Pesquisa da Potassa e do Fosfato. 1993, p.249-279.

Peiter, M.X. Comportamento do sorgo granífero (Sorghum bicolor Moench) quando submetido a diferentes níveis de irrigação. Santa Maria: UFSM. 1994. 82p. Dissertação Mestrado

Restle, J.; Neumann, M.; Alves Filho, D.C.; Pellegrini, L.G.; Souza, A. N.M.; Medeiro, S.M. Avaliação de características qualitativas e valor nutritivo da silagem de diferentes híbridos de sorgo (Sorghum bicolor L. Moench). In: Reunião Técnica Anual do Sorgo, 28, 2000, Pelotas. Anais.... Pelotas: FEPAGRO/ EMATER, 2000, p.403-411.

Steinmetz, S.; Maluf, J.R.T.; Matzenauer, R.; Amaral, A.G. Espacialização da temperatura do solo visando determinar o início da semeadura do arroz irrigado no estado do Rio Grande do Sul. In: Reunião da cultura do arroz irrigado, 24, e Congresso Brasileiro de Arroz Irrigado, 2, 2001, Porto Alegre. Anais... Porto Alegre: Instituto Riograndense do Arroz. 2001, p.137-139.

Toescher, C.F.; Köpp, L.M. Produtividade do arroz sob irrigação por aspersão em Uruguaiana, RS. In: Congresso da Cadeia Produtiva do Arroz. Florianópolis. Anais... Florianópolis: Embrapa Arroz e Feijão. 2002. p.405-406. 